Method This new programme does involve sessions to teach patients coping skills and is delivered by a multiprofessional team skilled in supporting patients with complex needs. Each week includes an exercise session and an opportunity to try several forms of relaxation. The programme is supported throughout with a cognitive behavioural therapies approach.

Results All patients are given a patient questionnaire as well as completing a Holistic Assessment of Needs Tool, an outcome measure completed prior to the group and afterwards to establish what benefit the group had made to patients' needs.

Pre and post exercise tolerance tests and evaluations are used. Conclusion Overall the results are extremely positive identifying that the 'Be in Charge' group was a real success. Therefore with the support from the hospice board of trustees we have now gained funding in order to deliver six programmes a year.

\section{P-108 EXERCISE IN PALLIATIVE CARE, GOING THE EXTRA MILE}

Emily Whiteoak. Hospice Care for Burnley and Pendle (Pendleside Hospice), UK

\subsection{6/bmjspcare-2016-001245.131}

Patients with life-limiting illnesses often experience functional impairment, resulting in poorer quality of life. Studies have shown that exercise can improve physical, emotional and psychological wellbeing, which all help maintain independence: Findings highlight that exercise in palliative care should not be viewed solely a physical intervention, but one that has potential to enhance many aspects of patients' quality of life (Turner et al., 2016)

As part of our rehabilitation service we aim to develop the exercise therapy element to meet the needs of the individual. We offer tailor made exercise programmes to achieve the best possible outcome for the patient.

The disease status or location of the individual patient is not a barrier to our service.

For example the rehabilitation assistant initially sees a patient in the outpatient setting. As disease progresses and status reduces the same patient maybe offered a different approach in the most appropriate setting.

This maybe

- Home

- Inpatient unit

- Day service unit

- Outpatients

- Group sessions

- $1: 1$.

It is acknowledged that the exercise therapy we deliver:

- Armchair exercise

- Tai Chi both seated and standing

- Circuit Training

- In house gym

- Balance, strength and coordination exercises

- Indoor and outdoor mobility

is offered in many hospice settings. What makes our service different is where our therapy can be delivered. It may be bold to say our service is totally unique but we are certain there is nothing equivalent in our immediate region.
The benefits are clear, regardless of the patient's changing condition we strive to maintain continuity making sure the individual is at the heart of everything we do; patients report after their exercise sessions they feel energised and it has given them the boost they need to carry on.

\section{P-109 CREATING A GROUP EXERCISE PROGRAMME TO SUIT THE VARIETY NEEDS OF ALL HOSPICE PATIENTS}

Nicola Silk, Patricia McGovern. Douglas Macmillan Hospice, Stoke on Trent, UK

\subsection{6/bmjspcare-2016-001245.132}

Aim To provide a group exercise programme to suit the variety of needs of all hospice In-patients, day therapy patients and community patients to enable them to exercise together as a group.

Background A group exercise session not only has physical benefits for patients, the social aspect of exercising together is extremely beneficial for patients in a hospice setting (Talbot Rice et al., 2014). Taking into account physical ability, medical conditions, needs and limitations of each individual person makes providing a group exercise a challenge.

Method Two hospice staff members trained as Tripudio Movement Instructors. The programme combines gentle stretching and strengthening in an aerobic exercise programme. It can be adapted to suit the individual needs of all patients, is done seated or standing and at any intensity level dependent on the individuals fitness level, physical ability and condition. Most importantly the sessions are fun.

Results The table below demonstrates the results of a 6 week programme held for one hour a week for ladies aged between $36 y r$ and $83 y r s$ with lymphoedema.

Following the program's success, the classes were adapted further to suit all day therapy, community and in- patients.

Conclusion Tripudio is an effective group exercise programme which can be adapted to enable patients with a variety of life-limiting conditions, symptoms and physical abilities to exercise together in a group setting.

\begin{tabular}{|c|c|c|}
\hline Medical conditions & Patient reported benefits & Additional comments \\
\hline Cancer & Reduction in lymphoedema & \\
\hline Bone metastases & Reduced pain & \\
\hline Lipodema & Reduction of breathlessness & \\
\hline Osteoarthritis & Reduction in analgesia & \\
\hline Underactive thyroid & Improved strength & Sessions are relaxing \\
\hline Surgical procedures & Improved balance & $\begin{array}{l}\text { Sessions are extremely } \\
\text { enjoyable }\end{array}$ \\
\hline Chronic pain & Improved mood & $\begin{array}{l}\text { Good to meet others } \\
\text { with similar conditions }\end{array}$ \\
\hline Asthma & Improved psychological health & Great fun \\
\hline Hypertension & Increased muscle tone & \\
\hline Heart failure & Increased mobility & \\
\hline Fractured humerus & Increased confidence & \\
\hline \multicolumn{3}{|l|}{ Atrial fibrillation } \\
\hline \multicolumn{3}{|l|}{ Osteoporosis } \\
\hline \multicolumn{3}{|l|}{ Diabetes } \\
\hline \multicolumn{3}{|l|}{ Total hip replacement } \\
\hline COPD & & \\
\hline
\end{tabular}

